Supplementary Information (S.I.)

\title{
Highly Sensitive Detection of Arsenite Based on Its Affinity toward Ruthenium Nanoparticles Decorated on Glassy Carbon Electrode
}

Ruma Gupta, $^{+*}$ Jayashree S. Gamare, ${ }^{\dagger}$ Ashok K. Pandey, ${ }^{\ddagger *}$ Deepak Tyagi, ${ }^{\ddagger}$ and Jayshree V. Kamat ${ }^{\dagger}$

${ }^{\dagger}$ Fuel Chemistry Division, ${ }^{\ddagger}$ Radiochemistry Division, ${ }^{*}$ Chemistry Division, Bhabha Atomic Research Centre, Trombay, Mumbai-400085, India

* Tel: +91-22-25594598; E-mail: ruma.chandra@gmail.com (RG), and Fax: +91-22-25505151;

Tel: +91-22-25594566; E-mail: ashokk@barc.gov.in (AKP). 


\section{Determination of electrochemical active surface area}

In order to measure the electrochemically active surface areas of the modified electrode, the cyclic voltammetry of $5 \mathrm{mM}$ potassium ferricyanide as the redox probe was recorded. In cyclic voltammetric studies, the current for the electrochemical reaction (at a mass-transferlimited rate) that diffuse to electrode surface is described by the Randle Sevick equation:

$$
I_{p}^{e}=2.69 \times 10^{5} n^{\frac{\pi}{2}} D^{\frac{1}{2}} A C_{0} v^{\frac{1}{2}}
$$

where $\mathrm{A}$ is the electrochemical active area, $\mathrm{D}$ is the diffusion coefficient, $\mathrm{C}$ is the bulk concentration of ferricyanide, $\mathrm{n}$ is the number of electrons transferred and $v$ is the scan rate.Under diffusion controlled process, a plot of $I_{p}^{\odot}$ vs $v^{1 / 2}$ will be linear and from the slope, the value of A can be obtained, since the precise value of the diffusion coefficient of ferricyanide is well known $\left(8.9 \times 10^{-6} \mathrm{~cm}^{2} \mathrm{~s}^{-1}\right)$. The electrochemically active area of the Bare GC was $0.015 \mathrm{~cm}^{2}$ and that of RuNPs/GC was $0.15 \mathrm{~cm}^{2}$.

Reference:

A.J. Bard and L. R. Faulkner, Electrochemical Methods, Fundamentals and Applications, Wiley, New York, (2001). 
Figure S1. Equivalent circuit used for fitting the impedance.

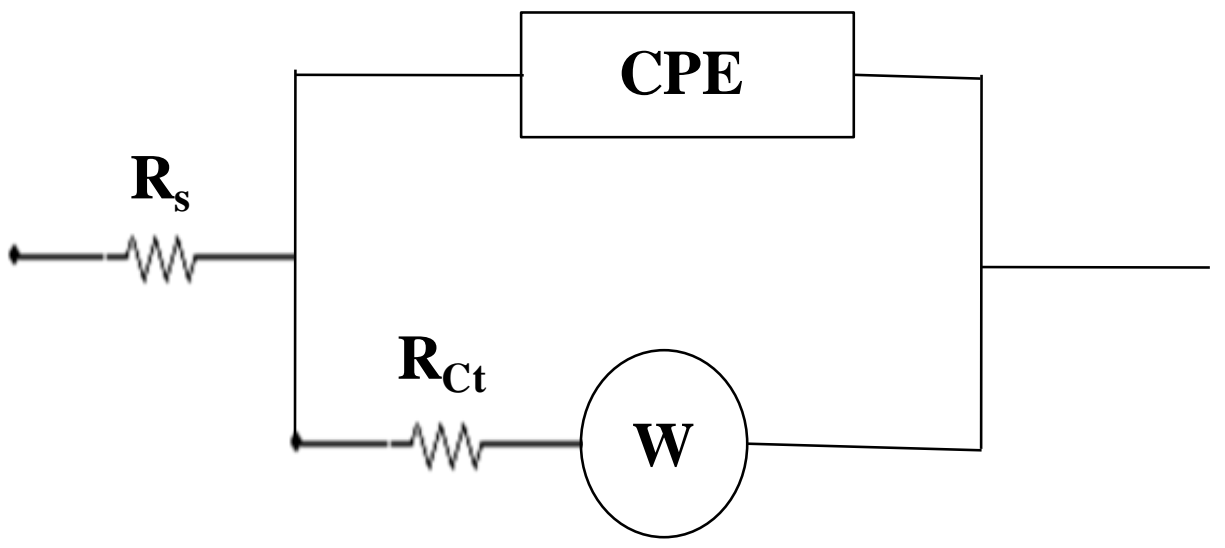


Figure S2. XPS spectra of Ru NPs decorated glassy carbon electrode.

(a)

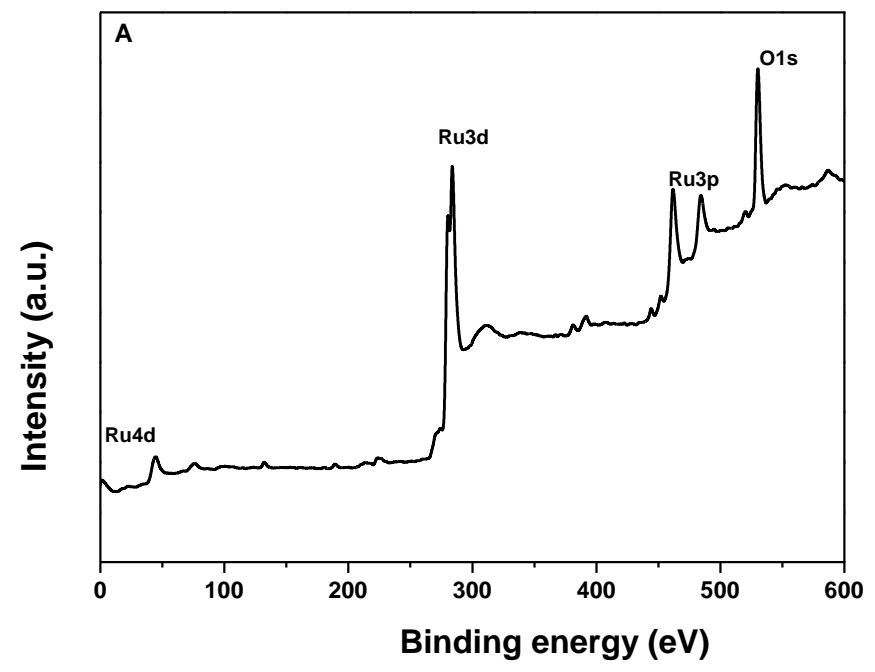

(b)

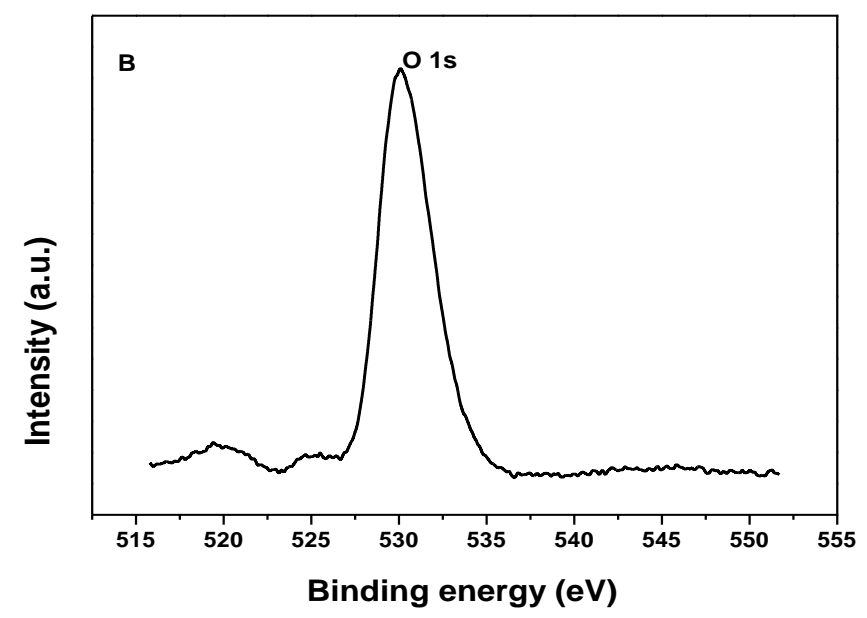

(c)

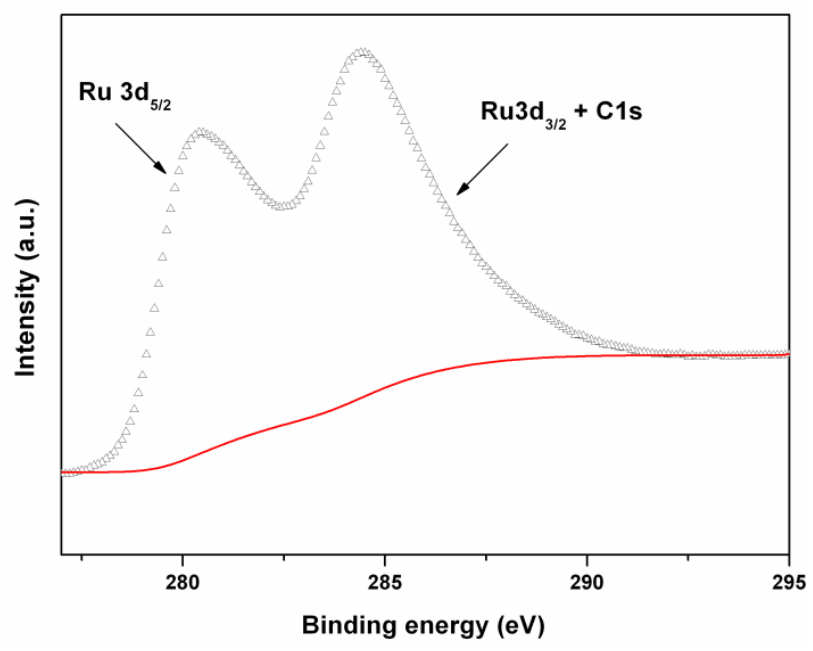


(d)

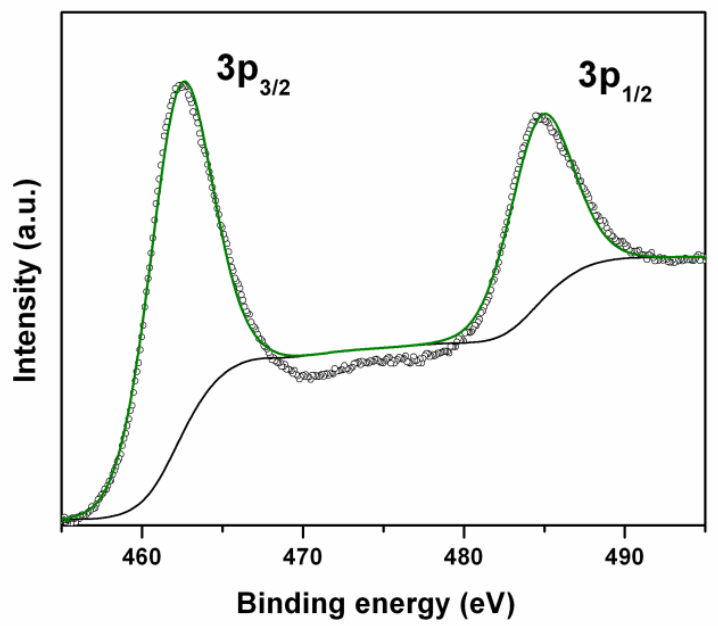


Figure S3.Comparison of XPS spectra before and after equilibration of RuNPs/GC with arsenite solution.

\section{Before}

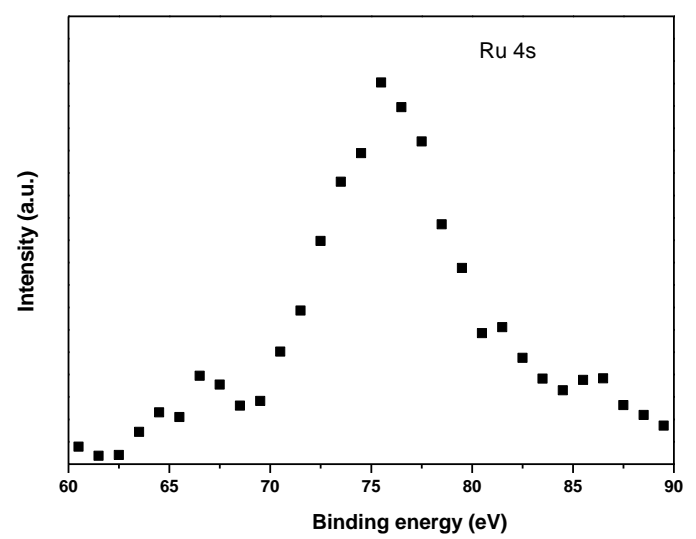

2. Before

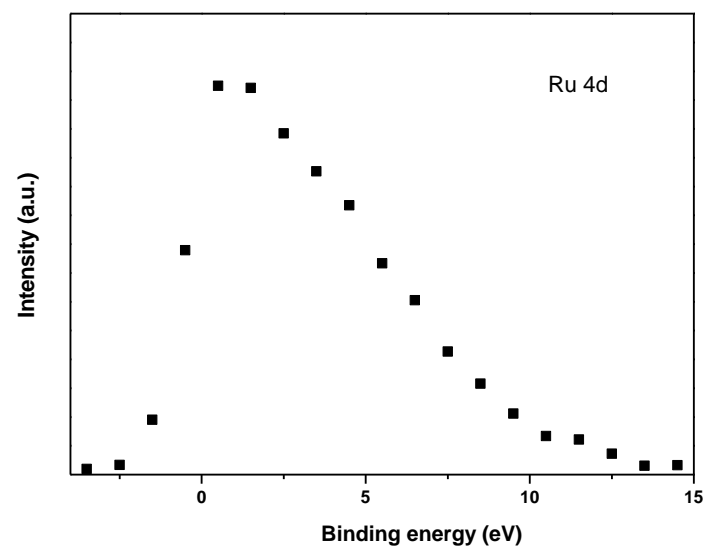

3. After

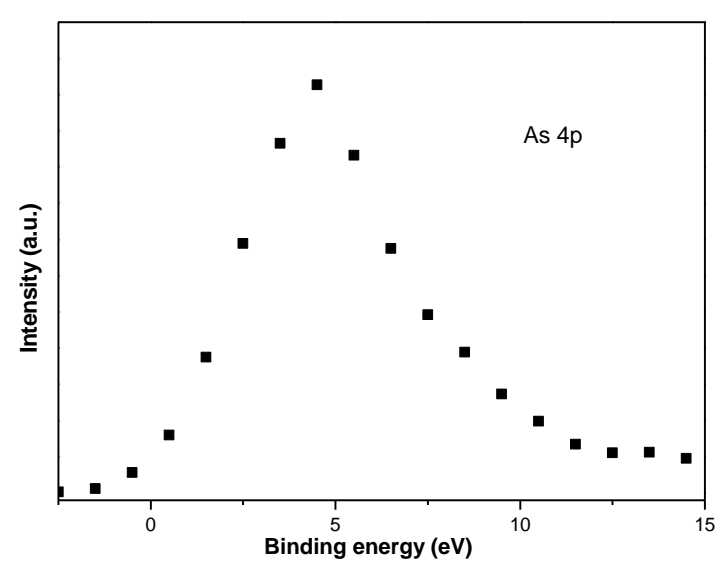

After

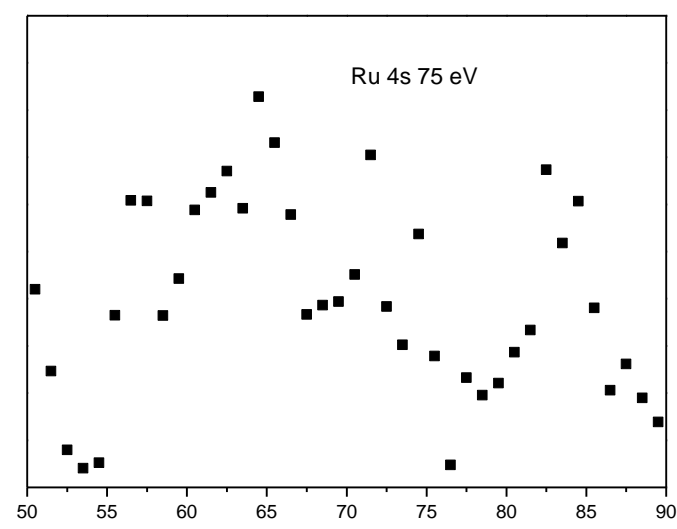

After

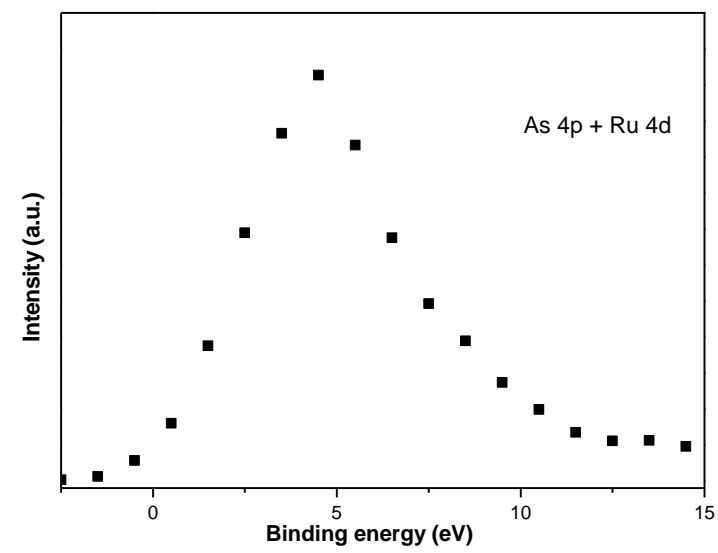

4. After

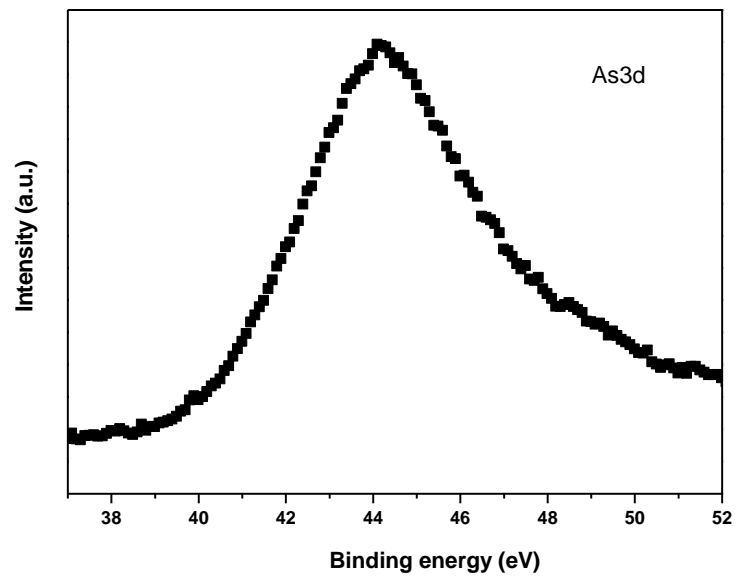


Figure S4.Cyclic voltammograms of RuNPs/GC electrode recorded at different scan rates in $1 \mathrm{mM} \mathrm{As(III)}$ in $\mathrm{pH} 2$ solution.

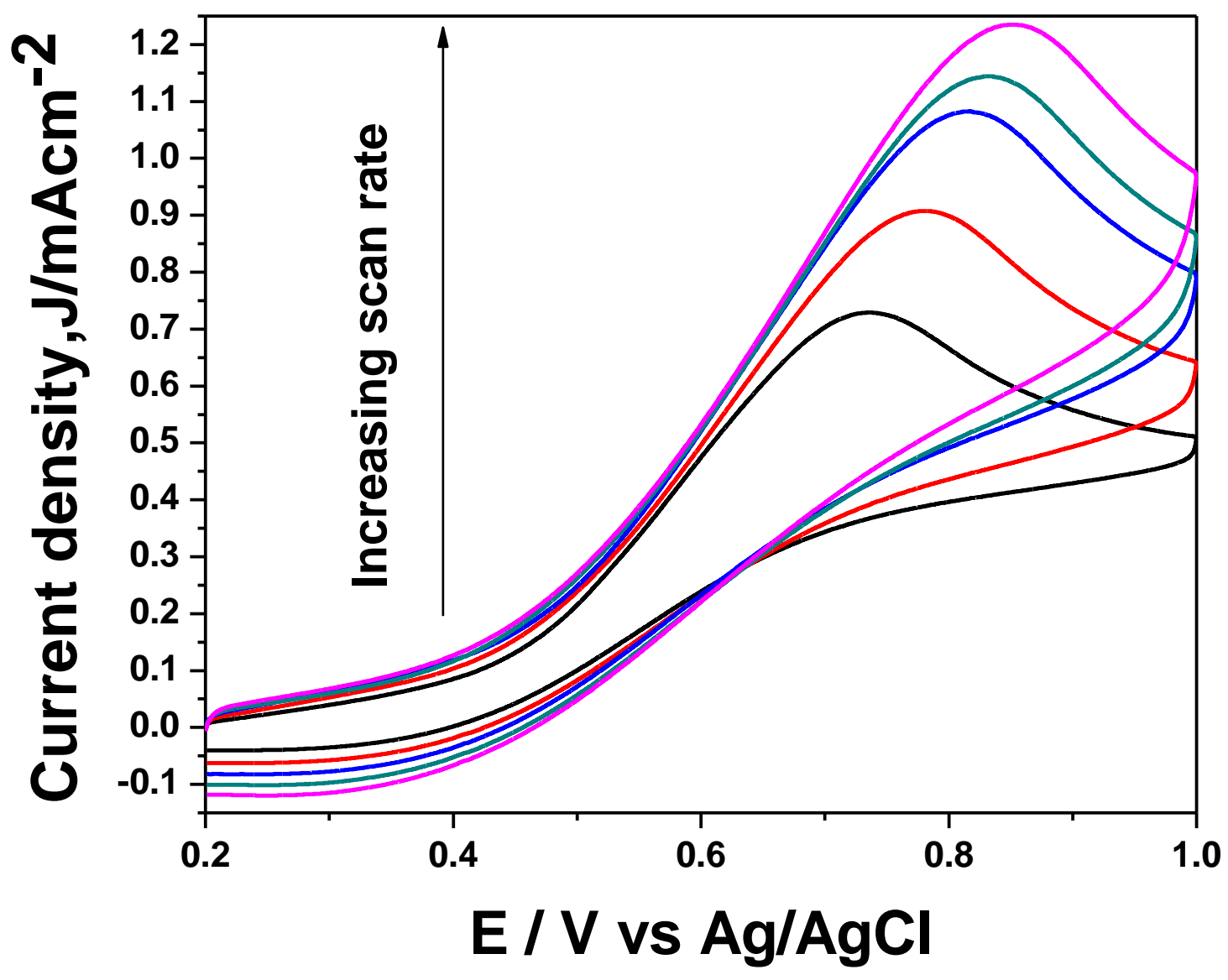


Figure S5.The plots of $\ln \mathrm{J}_{\mathrm{p}}$ versus $\ln (v)$ for the anodic peaks.

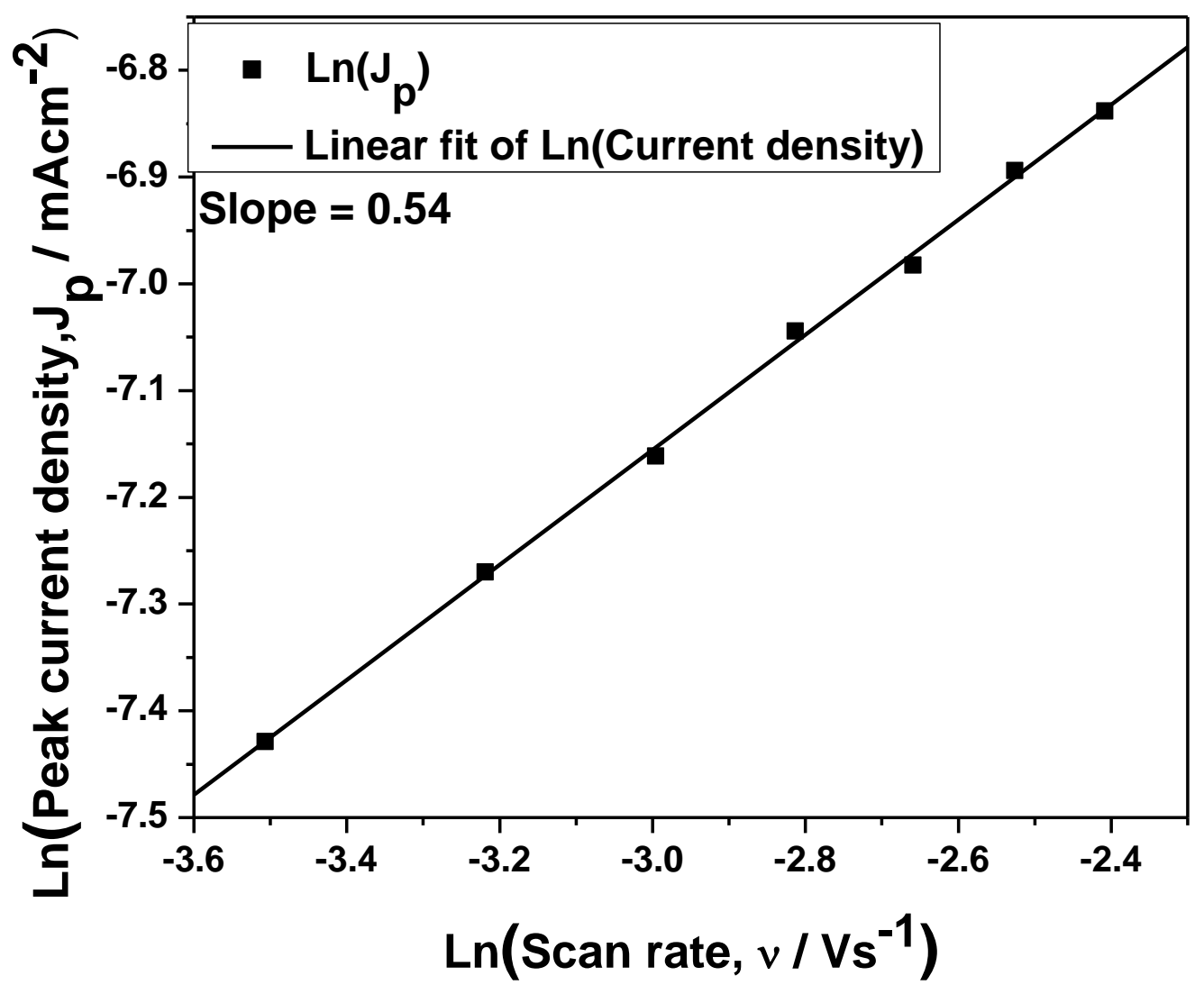


Figure S6. DPV of RuNPs/GC electrode in $1 \mathrm{mM} \mathrm{As(III)} \mathrm{in} \mathrm{Clark-Lubs} \mathrm{buffer} \mathrm{(pH} \mathrm{2)} \mathrm{with} \mathrm{with} \mathrm{0.1M} \mathrm{Cu(II)}$ ion in potential range $-0.2 \mathrm{~V}$ to $1 \mathrm{~V}$. Inset shows the DPV of same in potential range 0.4 to $1 \mathrm{~V}$.

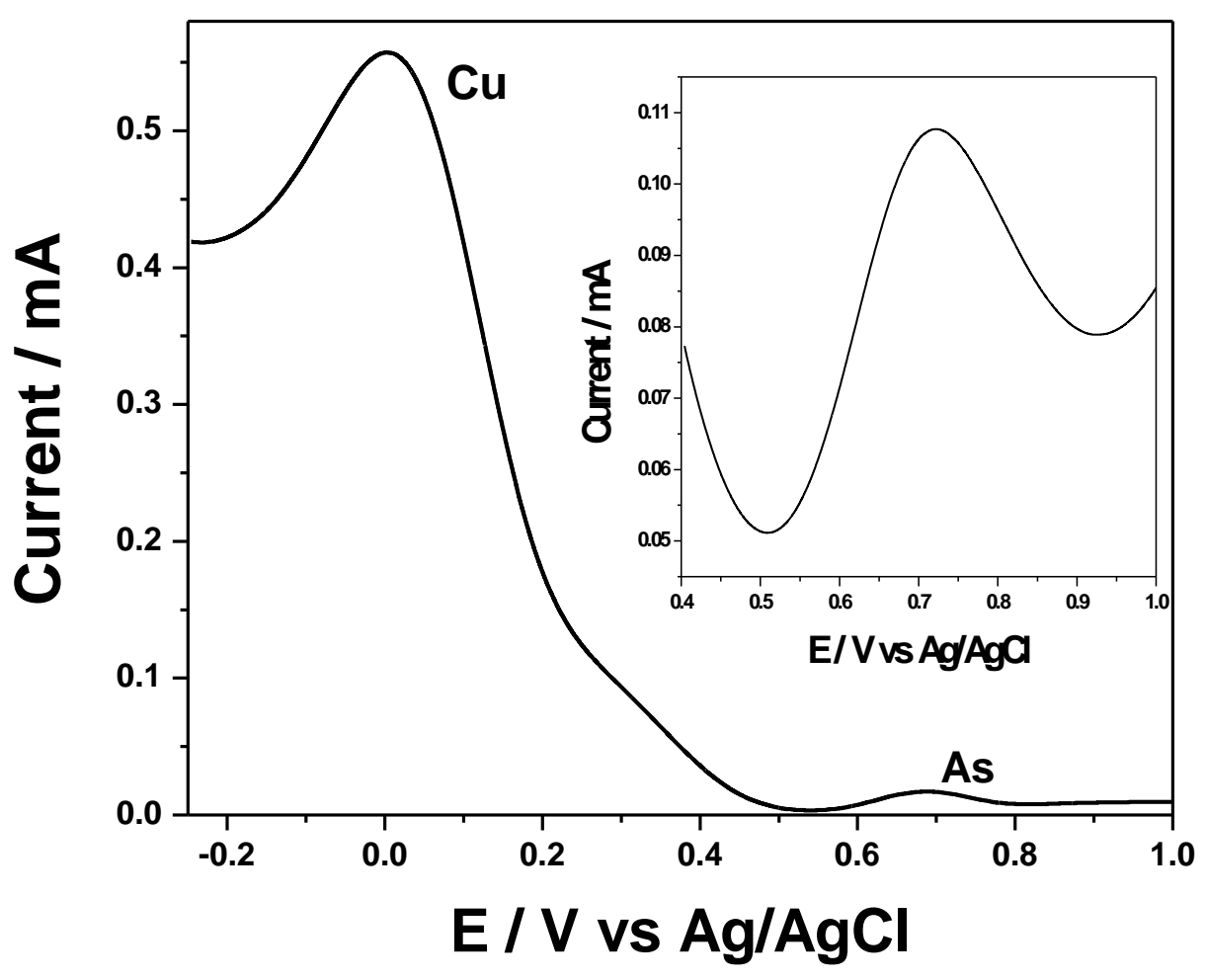

